\title{
SOBRE A POSSIBILIDADE DE ATIVIDADES EDUCATIVAS DE CARÁTER EMANCIPADOR
}

\author{
IN REGARD TO THE POSSIBILITY OF EMANCIPATION-BASED \\ EDUCATIONAL ACTIVITIES
}

lael de Souza ${ }^{1}$

\section{RESUMO}

Demonstrar e afirmar a natureza histórico-ontológica da educação como uma necessidade vital da autoconstrução humana e do gênero humano é uma tarefa essencial nos tempos hodiernos, porque dessa compreensão e clareza depende a possibilidade do educador se posicionar, criar e orientar suas atividades educativas para a edificação das práticas de caráter emancipador. $\mathrm{Na}$ luta contra-hegemônica, necessitamos fortalecer a perspectiva do trabalho contra a do capital.

Palavras-chave: emancipação - classes sociais - valores.

\begin{abstract}
Demonstrating and ensuring education's historical-ontological nature as a vital necessity of humanity's and human species' self-development is an essential task nowadays, since such comprehension and clarity bring about the possibility for the educator to know where they stand, to create and guide their educational activities in order to establish emancipation-based practices. In the antihegemonic battle, the labor versus capital perspective must be strengthened.
\end{abstract}

Keywords: emancipation - social classes - worth.

\section{INTRODUÇÃO}

Numa sociedade de classes, a educação é uma educação de classes. De modo que não haveria possibilidade de transformar o existente, pois a classe que detêm o controle sobre os meios de produção material e espiritual, controla a reprodução social. A única alternativa que restaria seria apenas aperfeiçoar e melhorar o que existe, já que o complexo social da educação acabaria reproduzindo as desigualdades sociais. 
A questão é que essa é a forma histórica adquirida pelo complexo social da educação numa dada forma de sociabilidade, que corresponde a um determinado período histórico-social que denominamos de capitalismo. Essa não é a natureza histórico-ontológica (essencial) da educação.

Cabe-nos, portanto, demonstrar e ratificar, junto com Tonet (2005) e Saviani (2008), guardadas suas especificidades substanciais - pois há discordâncias fundamentais entre eles -, qual seria essa natureza essencial da educação e a partir daí, da reposição do seu verdadeiro significado, que se faz urgente e imprescindível, delinear os critérios parametradores às atividades educativas de caráter emancipador (TONET, 2005, p. 225-237), demonstrando de que modo podemos atuar na imediaticidade para edificar as condições para a transformação radical da totalidade social, que é, essencialmente, mediata.

Também demonstraremos que é necessário um posicionamento de classe, de homem e de mundo (paidéia, no sentido grego) a fim de fortalecer a perspectiva do trabalho contra o capital. Mudanças de método, aulas, conteúdos, materiais, de relação ensino-aprendizagem sem esse posicionamento consciente, consequente e embasado racional, histórica, científica, filosófica e politicamente podem causar mais problemas do que auxiliar a superá-los, como demonstra a experiência de tentativa de implantação da Pedagogia Histórico-Crítica de Saviani por intermédio das políticas educacionais do Estado do Paraná (MAGALHÃES; SILVA JUNIOR, 2011), (BACZINSKI; PITON; TURMENA, 2008).

Hoje, mais do que em qualquer outro período da história humana, torna-se uma tarefa revolucionária fortalecer e afirmar o posicionamento de classe contra-hegemônico a fim de demonstrar que ainda que a emancipação humana esteja no horizonte da humanidade, é a possibilidade de vislumbrá-lo que nos anima a caminhar. Mais do que nunca, caminhar é preciso, ratificando, cultivando e construindo os meios e valores necessários para a realização daquele fim.

Assim, nunca é demais enfatizar a importância crucial da luta entre as perspectivas ideológicas do capital e do trabalho, porque dela resulta as tendências futuras para "que os indivíduos façam suas as objetivações comuns ao gênero humano, para poderem construir-se como membros desse gênero" (TONET, 2005, p. 231). 


\section{A NATUREZA HISTÓRICO-ONTOLÓGICA DA EDUCAÇÃO: EDUCAÇÃO NO SENTIDO AMPLO}

O ser humano tem uma dupla natureza: natural (biofísica; espécie) e social (autoconstrução humana; gênero). O orgânico é o repor o mesmo, que é a vida e o inorgânico é o tornar-se outro. $O$ salto qualitativo, que faz a síntese dialética e processual entre esses dois momentos é o surgimento do ser social, que é produzir, criar o novo, intervindo no mundo.

A educação, em seu sentido amplo, é parte do processo de tornar-se homem do homem. Se num primeiro momento, quando as atividades necessárias para a produção e reprodução social são simples e pouco numerosas, assim como a demografia e o espaço correspondente ocupado pelos seres humanos, a educação se realiza mediante o trabalho.

Porém, com a complexificação da vida social e das funções ligadas a sua reprodução, com a diversificação das atividades e dos meios de produção material, surge a necessidade de desenvolver conhecimentos, técnicas, habilidades, valores, comportamentos, etc. específicos, que devem ser transmitidos e assimilados pelas demais gerações a fim de que possam, a partir daí, desenvolver e criar outros, pois a satisfação das primeiras necessidades significa a criação de novas, de modo que o trabalho funda mas não esgota o ser social.

É assim que entendemos as continuidades e descontinuidades na processualidade e historicidade humanas e no fazer-se homem dos homens, pois assim como a complexificação do ser social necessita do momento do orgânico e inorgânico (a continuidade) para a produção/criação do novo (a descontinuidade na continuidade), assim também é necessário criar 0 complexo social da educação como forma de garantir a transmissão/assimilação do patrimônio histórico-cultural acumulado pela humanidade, construindo as bases para os avanços e novas intervenções/produções dos homens na história.

Vemos, portanto, que a natureza essencial da educação é que ela é histórico-ontológica, ou seja, imanente à processualidade de tornar-se homem do homem, da sua produção enquanto gênero humano, em outras palavras, incorporação das objetivações que constituem o patrimônio histórico-cultural 
das gerações anteriores ao longo do seu desenvolvimento histórico-social, apropriando-se, desta forma, dos conhecimentos, técnicas, habilidades, valores, comportamentos, etc. que Ihe permite transcender os limites históricosociais de outras gerações.

Nesse sentido, como afirma Tonet, "não se trata apenas de tomar posse de algo que já está pronto e acabado. Trata-se, também, neste processo, de apropriar-se do que já existe e de, ao mesmo tempo, recriá-lo e renová-lo, configurando, desse modo, o próprio indivíduo em sua especificidade" (TONET, 2005, p. 214). Do mesmo modo, Saviani confirma o caráter histórico-ontológico da educação ao dizer que "o que não é garantido pela natureza tem que ser produzido historicamente pelos homens, e aí se incluem os próprios homens. (...) a natureza humana não é dada aos homens, mas é por ele produzida sobre a base da natureza biofísica" (SAVIANI, 2008, p. 13).

Logo, a educação, em seu sentido amplo, isto é, enquanto complexificação das sociabilidades humanas e da reprodução social, "é o ato de produzir, direta e intencionalmente, em cada indivíduo singular, a humanidade que é produzida histórica e coletivamente pelo conjunto dos homens" (SAVIANI, 2008, p. 13), para que, assim, seja possível identificar os "elementos culturais que precisam ser assimilados pelos indivíduos da espécie humana para que eles se tornem humanos" (SAVIANI, 2008, p. 13), constituindo-os como membros do gênero humano.

\section{POSICIONAMENTO DE CLASSE, DE HOMEM E DE MUNDO (PAIDEIA, NO SENTIDO GREGO)}

A clareza e domínio sobre a natureza histórico-ontológica da educação deve ser um pressuposto, orientando o educador na tomada de posição e nas decisões referentes às atividades educativas e aos meios mais adequados e aproximativos ao fim a se objetivar, demonstrando que os meios precisam estar de acordo com os fins, qualificando-os. As escolhas realizadas, ainda que limitadas e delimitadas pelas circunstâncias e condições históricosociais que independem da vontade dos indivíduos, "poderão influenciar as 
outras dimensões sociais em sentidos diversos, ou seja, mais no sentido de frear ou de impulsionar a mudança" (TONET, 2005, p. 216).

Ao orientar suas ações educativas, mesmo tendo por base a natureza específica e essencial da educação, o educador também faz um posicionamento de classe, dado que o que os indivíduos são "coincide (...) com sua produção, tanto com o que produzem como também com o modo como produzem. O que os indivíduos são, portanto, depende das condições materiais de sua produção", (MARX; ENGELS, 2007, p. 87) do lugar que ocupam na estrutura socioprodutiva fundada na divisão social do trabalho.

Sendo assim, numa forma de sociabilidade fundada sobre a propriedade privada dos meios e bens de produção material e espiritual, aprofundando as desigualdades sociais entre os homens, mantida e reproduzida através da divisão social, hierárquica, jurídica e política do trabalho, os educadores precisam assumir seu lugar enquanto classe social, porque dela decorre uma determinada (determinação reflexiva, síntese de múltiplas determinações) e condicionada concepção de homem, de sociedade e de mundo, como também de conhecimentos, habilidades, valores, comportamentos, objetivos, etc., a serem buscados e realizados.

O posicionamento de classe é constituinte do processo das relações de poder e força estabelecido entre a perspectiva do capital e do trabalho, uma luta que dependendo das condições de organização e mobilização das classes, dos momentos e acontecimentos históricos-sociais específicos produzidos, pode utilizar do Poder (aparelhos repressivos de estado) ou da persuasão (aparelhos ideológicos de estado) para atingir seus objetivos. Porém, dentre eles o mais eficaz e que encontra menos resistência organizada, é a ideologia e, no caso, a de classe, pois justifica o modo como os homens vivem, pensam, sentem, criando e inculcando determinados valores que passam a influenciar de maneira decisiva na escolha entre alternativas feitas pelos indivíduos, ainda que ela seja, como frisamos, limitada e relativa.

Nesse contexto, a educação adquire um importante papel, podendo contribuir para aperfeiçoar o existente, ou para questioná-lo, procurando reconstituir seus nexos causais e as condições para romper com ele e superálo, o que dependerá do posicionamento de classe do educador, reforçando uma ou outra perspectiva, pois sua matéria prima são as consciências dos 
sujeitos. Eis uma das características da educação, seu objeto é ao mesmo tempo sujeito, de modo que não se trata de uma relação apenas entre sujeito e objeto, mas entre sujeito e objeto que é também sujeito, dado que 0 ato educativo corresponde "a ação sobre uma consciência visando induzi-la a agir de determinada forma" (TONET, 2005, p. 218) e não de outra. De modo que o educador pode contribuir para frear ou acelerar a mudança porque questiona os fundamentos objetivos, histórico-ontológicos dos valores humanos.

No entanto, é importante destacarmos que a perspectiva do trabalho é a única capaz de realizar a transcendência positiva, rompendo definitivamente com o capital e o capitalismo ao superar o trabalho assalariado, a propriedade privada, a existência das classes sociais, a divisão social do trabalho e o Estado, tornando todos os homens trabalhadores, produtores livremente associados, como demonstraram Marx e Engels (1989), restituindo à educação seu caráter verdadeiramente histórico-ontológico, criando as condições objetivas e subjetivas à realização da paideia humana, no seu sentido grego, que não se restringe à cultura, convertida, atualmente, num simples conceito antropológico descritivo.

Para os gregos, a paideia significava um alto conceito de valor, um ideal objetivo, consciente, e não um aspecto exterior da vida. Na paidéia grega está presente a ideia de uma educação do homem de acordo com a verdadeira forma humana, com o seu autêntico ser (ontologia). Não se pode evitar o emprego de expressões modernas como: civilização, cultura, tradição, literatura ou educação; nenhuma delas, porém, coincide realmente com o que os gregos entendiam por paideia. Cada um daqueles termos se limita a exprimir um aspecto daquele conceito global e, para abranger o campo total do conceito grego, teríamos de empregá-los todos de uma só vez. ${ }^{2}$ 


\title{
DA NATUREZA ESSENCIAL DA EDUCAÇÃO ÀS ATIVIDADES EDUCATIVAS DE CARÁTER TRANSFORMADOR: NÃO BASTA UM MÉTODO REVOLUCIONÁRIO
}

A partir do momento que o educador domina a compreensão da natureza essencial da educação, tendo realizado sua tomada de posição perante as perspectivas de homem e de mundo que deseja contribuir para edificar, consciente das implicações contidas nessa escolha, e de que embora a hegemonia das condições da produção e reprodução social esteja nas mãos da classe capitalista, é possível criar as condições para propiciar o desenvolvimento de atividades educativas de caráter transformador, isto porque, como esclarece Tonet,

\begin{abstract}
A existência do antagonismo de classe (...) também implica no surgimento - sob formas explícitas ou implícitas - de outras propostas, com outros fundamentos, outros valores e outros objetivos. De modo que o campo da educação, como aliás toda a realidade social, é um espaço no qual se trava uma incessante luta, ainda que a hegemonia esteja sempre nas mãos das classes dominantes. Essas outras propostas, no entanto, sempre terão um caráter restrito, pontual, isolado. No caso da sociedade atual, uma proposta de educação emancipadora só poderá ser explicitada em seus elementos gerais, mas nunca poderá ser levada à prática como um conjunto sistematizado. A disputa certamente pode e deve ser efetuada, posto que o processo histórico, sendo constituído de atos humanos individuais marcados por algum grau de liberdade, não tem os seus resultados previamente determinados. E deve ser efetuada nos mais diversos campos: das ideias, dos conteúdos, dos programas, dos métodos, dos recursos, dos espaços, das tecnologias, das políticas educacionais, etc. Não se pode nutrir, todavia, a ilusão de estruturar uma educação emancipadora como um conjunto sistematizado e amplamente praticável em oposição a uma educação conservadora. (TONET, 2005, p. 223)
\end{abstract}

A utilização de um método revolucionário não seria garantia para transição do senso comum à consciência filosófica (SAVIANI, 2004, 2008), (LAZARINI, 2010), muito menos a exigência de sua aplicação através de uma pedagogia tornada política educacional, como o caso da Pedagogia HistóricoCrítica (MAGALHÃES; SILVA JUNIOR, 2011) e as experiências resultantes de sua implantação no estado do Paraná (BACZINSKI; PITON; TURMENA, 2008), justamente por estar na contramão da formação histórico-científica, políticosocial da maioria dos professores da rede de ensino, cujas ideias, valores inculcados e reproduzidos que guiam sua práxis os aproxima muito mais da 
perspectiva do capital do que do trabalho, ainda que digam e acreditem, ingenuamente, no contrário.

Não basta utilizar um método novo, trabalhar os conteúdos de outra forma, tentar estabelecer uma relação ensino aprendizagem diferenciada. $O$ embasamento de todos esses meios e recursos deve pautar-se na clareza e domínio da natureza essencial da educação e de suas possibilidades e limites na sociabilidade capitalista, bem como num posicionamento de classe e na escolha de uma perspectiva de mundo, envolvendo uma concepção de homem e de sociedade (paideia).

Não desconsideramos que a educação escolar sistematiza e socializa o saber acumulado pelos homens. Porém, justamente por ser um dos aparelhos ideológicos de estado e estar sobre a hegemonia da classe dominante, esse saber é apropriado por ela, colocado a serviço dos seus interesses, legitimado e autenticado cientificamente através do método epistemológico/gnoseológico e não ontológico, não havendo possibilidade de trabalhar em termos de "conteúdos concretos", entendido por Saviani como a captura do movimento do real em suas múltiplas relações através da reflexão dialética, da mediação do abstrato, do concreto pensado, pensando por contradição. Afinal, os conflitos, as contradições, para a ciência social positiva são explicados como disfunções e como tais devem ser corrigidas, amenizadas, consertadas. ${ }^{3}$

Sendo o método epistemológico/gnosiológico o norteador da elaboração do saber que é produzido empiricamente, socialmente, a passagem do senso comum à consciência filosófica, requisitada por Saviani, fica comprometida, porque pressupõe a ontologia, a historicidade, a totalidade social e a dialética. Um agravante desse quadro conjuntural é a transformação da ideologia das classes dominantes em "senso comum", demonstrando as contradições implicadas na conjuntura histórico-social complexa desse conceito:

a concepção de mundo hegemônica é exatamente aquela que, mercê de sua expressão universalizada e seu alto grau de elaboração, logrou obter o consenso das diferentes camadas que integram a sociedade, vale dizer, logrou converter-se em senso comum. E nesta forma, isto é, de modo difuso, que a concepção dominante (hegemônica) atua sobre a mentalidade popular articulando-a em 
torno dos interesses dominantes e impedindo ao mesmo tempo a expressão elaborada dos interesses populares, o que concorre para inviabilizar a organização das camadas subalternas enquanto classe. O senso comum é, pois, contraditório, dado que se constitui num amálgama integrado por elementos implícitos na prática transformadora do homem de massa e por elementos superficialmente explícitos caracterizados por conceitos herdados da tradição ou veiculados pela concepção hegemônica acolhidos sem crítica. (SAVIANI, 2004, p. 2)

De modo que a educação escolar é política, ideológica e hegemonicamente conservadora, e mesmo as tentativas de implementação de uma nova política educacional, através de uma pedagogia e de um método revolucionários, acabam esbarrando nas limitações histórico-científico, políticofilosóficas dos profissionais da educação, formados, ao longo do seu processo de escolarização, via de regra, pela perspectiva hegemônica do capital, cujo "pensamento e atuação críticos" não ataca os problemas sócio-produtivoseducacionais em sua raiz, tendo como teto os limites da cidadania; da conquista por "mais" direitos, "mais" igualdade e "mais" liberdade; a participação cidadã e outras correlatas, sem confrontar, visceralmente, o próprio capital e seu sistema metabólico de reprodução social, mantendo as bases da desigualdade social e da sociabilidade capitalista.

Se a consciência de classe passa pela questão do domínio do saber, como afirma Saviani (2008, p. 78), isso é extremamente complicado, ainda mais se considerarmos a exposição realizada, em linhas gerais, dos instrumentos lógico-metodológicos sobre os quais se estrutura e é sistematizado esse saber e conhecimento científico, como também o escolar. Mas ainda fica pior, a partir do momento que Saviani afirma que:

\footnotetext{
a passagem do senso comum à consciência filosófica é condição necessária para situar a educação numa perspectiva revolucionária. Com efeito, é esta a única maneira de convertê-la em instrumento que possibilite aos membros das camadas populares a passagem da condição de 'classe em si' para a condição de 'classe para si'. Ora, sem a formação da consciência de classe não existe organização e sem organização não é possível a transformação revolucionária da sociedade. (SAVIANI, 2004, p. 6)
}

E arremata: "O povo precisa da escola para ter acesso ao saber erudito, ao saber sistematizado e, em consequência, para expressar de forma elaborada os conteúdos da cultura popular que correspondem aos seus interesses" (SAVIANI, 2008, p. 80). 
O problema é que se essa "expressão de forma elaborada dos conteúdos da cultura popular" for realizada através do método científico vigente, embasado na episteme e na gnoseologia e não na ontologia, como deveria ser, a superação da contradição presente na construção do senso comum, cuja tônica é a reprodução da idelogia da classe dominante, torna-se inviável.

Parece que chegamos a uma encruzilhada e é chegado o momento de tomar uma outra direção, que não diz muito respeito aos instrumentos lógico-metodológicos, mas aos requisitos essenciais para o desenvolvimento de atividades educativas de caráter emancipador.

\section{CONSIDERAÇÕES FINAIS: SOBRE A POSSIBILIDADE DE ATIVIDADES EDUCATIVAS DE CARÁTER EMANCIPADOR}

Como vimos, considerando a forma de sociabilidade histórico-social atual, a perspectiva hegemônica é a conservadora, positivista, funcionalista. Porém, seu controle e poder jamais são absolutos, ainda que procure ostentar o contrário. Sempre há brechas, porque a realidade é contraditória, dialética, processual e as escolhas individuais, ainda que relativas e determinadas circunstancialmente, porque condicionadas histórica e socialmente, influenciam nas consequências das ações humanas. Daí a imprevisibilidade do "rio tempestuoso da fortuna", como dizia Nicolau Maquiavel, e a possibilidade de mudanças radicais e rupturas pela profunda e substancial transformação no curso dos acontecimentos.

Tonet nos lembra que as escolhas são fundadas em valores, sejam elas conscientes ou inconscientes e que o fim último que deve guiar o educador em suas ações educativas é, "obviamente, o valor por excelência" (TONE, 2005, p. 230). Contudo, ressalva que "não se trata de quaisquer valores, mas de valores histórica e socialmente fundados, ou seja, valores que tendo a sua base no processo real apontam para uma forma superior de sociabilidade" (TONET, 2005, p. 231). De modo que "não há receituário do que seja a atividade educativa emancipadora, (...) não está pré-estabelecido o que seja uma atividade educativa emancipadora nas suas expressões cotidianas. Tem-se, hoje, apenas parâmetros gerais. De modo que é preciso criar" 
(TONET, 2005, p. 231). Ainda assim, o que antecede e funda essas ações educativas emancipadoras é a imprescindível clareza da natureza ontológica essencial da educação.

Assim, retomando a questáo da cria;áo das atividades educativas emancipadoras, Tonet (2005) afirma que ainda que ela seja subjetiva, é uma subjetividade objetivada, pois parte da necessária e adequada compreensão da objetividade e processualidade histórico-social do real, ou seja, das múltiplas determinações e mediações existentes entre os objetos, que por estarem no mundo com ele se relacionam e são afetados por essas relações - sociais e de produção.

Daí decorre o primeiro requisito, segundo o autor, para uma atividade educativa de caráter emancipador, traduzindo o próprio fim maior da educação, ou seja,

o conhecimento, o mais profundo e sólido possível da natureza do fim que se pretenda atingir, no caso, a emancipação humana. Se é verdade que o fim qualifica (não justifica) os meios e se é verdade que a educação é uma mediação entre o indivíduo e a sociedade, então não há dúvida de que só se pode saber quais meios são adequados quando se tem clareza acerca do fim a alcançar. (TONET, 2005, p. 226)

Por sua vez, pressupõe um posicionamento de mundo em consonância com o lugar ocupado na produção social, e a coragem para assumi-lo e mantê-lo, arcando com as consequências que certamente virão, pois há um preço a pagar ao compreender e denunciar a essência do modo de produção capitalista e do metabolismo do capital, uma luta de classes permanente, encarniçada e virulenta, a travar, a fim de construir as condições que permitirão ir além do capital e da sociabilidade capitalista, superando-os radicalmente.

O segundo requisito corresponde "a apropriação do conhecimento a respeito do processo histórico real, em suas dimensões universais e particulares", uma vez que "quem faz educação, necessita de uma frequência constante e intensa ao saber produzido pelas Ciências Sociais" (TONET, 2005, p. 232), ainda que esse saber também não baste, já que aquelas são produzidas sobre a hegemonia da ciência positivista, e da teoria epistemológica/gnoseológica e não da ontologia que, por sua vez, tem por princípio a totalidade social, inseparável "da afirmação de que o processo de 
produção material é a matriz ontológica do ser social” (TONET, 2005, p. 233). Assim, é necessário "passar a limpo" a produção das Ciências Sociais tendo por base essa matriz.

O terceiro "está no conhecimento da natureza essencial do campo específico da educação" (TONET, 2005, p. 233), qual seja, "possibilitar ao indivíduo a apropriação daquelas objetivações que constituem o patrimônio comum da humanidade", tendo como pressuposto a "luta pelas condições que permitam atingir o mais plenamente possível este objetivo. Dessa forma o indivíduo se constituirá como um ser pertencente ao gênero humano e contribuirá para a reprodução deste" (TONET, 2005, p. 236).

O quarto e penúltimo requisito diz respeito "ao domínio dos conteúdos específicos, próprios de cada área do saber" (TONET, 2005, p. 234), articulados com a prática social. É esse domínio do saber, sua difusão e articulação com os problemas sociais vividos pelos homens que faz de um educador um "educador emancipador", porque além de dominar, difundir e construir um conhecimento mediado pela objetividade do real, todo educador que se posicione numa perspectiva ontológica, também contribui para a formação de outros valores, atitudes, comportamentos, objetivos, enfim, de uma outra paideia.

Por fim, o quinto e último requisito das atividades educativas de caráter emancipador está na "articulação da atividade educativa com as lutas desenvolvidas pelas classes subalternas, especialmente com as lutas daqueles que ocupam posições decisivas na estrutura produtiva" (TONET, 2005, p. 235). Cabe ao educador-pesquisador-intelectual, como defende e demonstra Giroux (1997), auxiliar a perspectiva do trabalho e os trabalhadores na captura, aproximação e reflexão da processualidade, objetividade e historicidade do real, já que encontram sérios entraves para avançar nesse árduo e penoso trabalho devido o lugar que ocupam na produção social. Conforme Tonet,

O avanço no cumprimento da tarefa mais essencial da educação que, como vimos, é a apropriação daquelas objetivações que constituem o patrimônio comum da humanidade, não depende só e nem principalmente da atividade educativa, mas do progresso na luta, realizada pelo conjunto das classes subalternas, para contrapor-se à hegemonia do capital Ou seja, muitas das condições para a realização da atividade educativa são externas ao campo da própria educação e só podem ser conquistadas com uma luta mais ampla, no 
entanto a concretização desta articulação é, hoje, uma tarefa extremamente difícil e complexa. (...) A realização desta tarefa essencial é sempre o momento determinante da atividade educativa. Outros momentos - atividades sindicais, lutas econômicas, políticas, etc. - são imprescindíveis e, em certas circunstâncias, poderão até assumir o papel de momento predominante. É preciso ter bem claro, porém, que de modo algum se pode inverter a relação entre esses dois momentos, sob pena de eliminar o caráter emancipador da atividade educativa. (TONET, 2005, p. 236 e 237)

Evidencia-se, portanto, que a transformação radical da sociedade não é papel da educação, mas do trabalho na perspectiva da ontologia do ser social, na forma histórico-social do trabalho associado, que não é o foco da análise, embora conectado, através de múltiplas determinações, a ela, mas que exige uma reflexão específica e outras mediações objetivas para ser compreendido, não comportadas aqui.

Logo, à educação, em sentido amplo, cabe a contribuição na construção dos meios qualitativamente adequados para a maior aproximação possível do fim, que é a emancipação humana. Isso significa dizer que não são quaisquer meios, como já foi frisado, nem qualquer patrimônio históricocultural, mas aquele selecionado através do critério dos valores, conhecimentos, objetivos fundamentais que fundamentam o desenvolvimento, o mais pleno e integral possível, do ser social, numa perspectiva históricaontológica.

\section{REFERÊNCIAS BIBLIOGRÁFICAS}

BACZINSKI, Alexandra V. de M; PITON, Ivania M.; TURMENA, Leandro. Caminhos e descaminhos da prática docente: uma análise da Pedagogia Histórico-Crítica e das diretrizes curriculares do Estado do Paraná. Revista HISTEDBR On-Line, Campinas, n. 31, p. 142-152, set. 2008.

GIROUX, Henry A. Os professores como intelectuais: rumo a uma pedagogia crítica da aprendizagem. Trad. Daniel Bueno. Porto Alegre: Artmed, 1997.

LAZARINI, Ademir Quintilho. A relação entre capital e educação escolar na obra de Dermeval Saviani. (Tese de Doutorado). Universidade Federal de Santa Catarina. Centro de Ciências da Educação. Programa de PósGraduação em Educaçao. Florianópolis, Santa Catarina, 2010. 
MAGALHÃES, Carlos Henrique Ferreira; SILVA JUNIOR, João dos Reis. Desafios para objetivação da Pedagogia Histórico-Crítica na prática escolar. Linhas Críticas, Brasília, DF, v. 17, n. 32, p. 113-135, jan./abr. 2011.

MARX, Karl; ENGELS, Friedrich. A Ideologia Alemã: crítica da mais recente filosofia alemã em seus representantes Feuerbach, B. Bauer e Stiner, e do socialismo alemão em seus deferentes profetas (1845-1846). Supervisão editorial, Leandro Konder; tradução, Rubens Enderle, Nélio Schneider, Luciano Cavini Martorano. São Paulo: Boitempo, 2007.

Manifesto do Partido Comunista - incluindo os prefácios às diversas edições do Manifesto e, entre outros anexos, Princípios do Comunismo e Para a História da Liga dos Comunistas, de Engels. Marco Aurélio Nogueira (Organização e Introdução). Trad. Marco Aurélio Nogueira; Leandro Konder. $2^{\mathrm{a}}$ ed. Petrópolis, RJ: Vozes, 1989.

SAVIANI, Dermeval. Pedagogia Histórico-Crítica - primeiras aproximações. 10 ed. rev. Campinas, SP: Autores Associados, 2008. (Coleção educação contemporânea)

- Educação - do senso comum à consciência

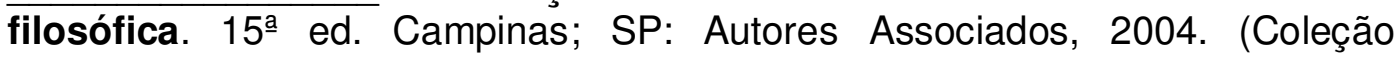
educação contemporânea)

TONET, Ivo. Educação, Cidadania e Emancipação Humana. ljuí: Ed. Unijuí, 2005. (Coleção fronteiras da educação)

\footnotetext{
1 Professora da Universidade Federal do Piauí. Mestre em Ciências Sociais pela UNESP-Marília/SP. Depto de Ciências Humanas e Educação. Pesquisadora do LABOR, UFC/CE. Coordenadora do Projeto de Pesquisa GEMPI, da UFPI/Picos. Email: iaeldeo@gmail.com.

${ }^{2}$ Ver JAEGER, Werner Wilhelm. Paideia - a formação do homem grego. Trad. Artur M. Parreira. 3a ed. São Paulo: Martins Fontes, 1995, p. 3 - 20)

${ }^{3}$ Ver, SOUZA, lael de. Da necessidade de uma ciência do social: condições e circunstâncias histórico-sociais e perspectiva hegemônica de atuação. Picos: PI, 2013. (no prelo)
}

RECEBIDO EM: novembro/2014

APROVADO EM: dezembro/2014 